\title{
STEROID BIOSYNTHESIS IN VITRO BY FOETAL AND ADULT SHEEP ADRENAL TISSUE
}

\author{
A. B. M. ANDERSON, G. G. PIERREPOINT, T. JONES, \\ K. GRIFFITHS AND A. C. TURNBULL \\ Tenovus Institute for Cancer Research and \\ Department of Obstetrics and Gynaecology, \\ The Welsh National School of Medicine, Cardiff
}

(Received 2nd May 1969, revised 25th August 1969)

\begin{abstract}
Summary. The metabolism, in vitro, of isotopically-labelled pregnenolone and progesterone by foetal and adult sheep adrenals has been investigated. Both substrates were almost completely metabolized by the adult tissue, whereas, in the case of the foetus, only pregnenolone showed extensive metabolism. The adult adrenal converted pregnenolone mainly to cortisol, corticosterone and 11-deoxycortisol, whereas corticosterone was the major product from progesterone. The foetal adrenal, on the other hand, yielded mainly progesterone from pregnenolone with only a small conversion to the corticosteroids. The substrate, progesterone, was transformed, in the main, to 11-deoxycorticosterone. No $3 \beta$-hydroxysteroid sulphokinase-transferase activity was demonstrated in either tissue. The importance of these findings and the probable pathways involved in the formation of the biosynthetic products are discussed.
\end{abstract}

\section{INTRODUCTION}

Information on the secretion of cortisol and corticosterone by the adrenal cortex of the foetal and adult sheep has appeared frequently in the literature (Blair-West, Goghlan, Denton, Goding, Wintour \& Wright, 1963; Chester Jones, Jarrett, Vinson \& Potter, 1964; Alexander, Britton, James, Nixon, Parker, Wintour \& Wright, 1968), but little attempt has been made to study the principal pathways for their biosynthesis in this species. Vinson (1967) and Vinson \& Whitehouse (1967) have assessed the rôle of 21-hydroxypregnenolone in the synthesis of corticosterone from pregnenolone.

Moreover, interest in corticosteroid production by the ovine foetal adrenal gland has been aroused by the work of Liggins (1968), who showed that parturition could be induced prematurely in the sheep by the continuous infusion over several days of cortisol or synthetic corticotrophin into the lamb in utero. A recent paper by Bassett \& Thorburn (1969) also implicated foetal adrenal corticosteroid secretion in the initiation of parturition in the sheep.

As part of a programme of investigation on the metabolism of steroids by 
the pregnant sheep, its foetus and placenta, this initial study is concerned with the biosynthesis of various steroids, particularly corticosteroids, from pregnenolone and progesterone by both foetal and adult sheep adrenal tissue incubated in vitro. The findings will form a basis for future work on the metabolism of steroids in these tissues at different stages of gestation and under the influence of various stimuli.

\section{MATERIALS AND METHODS}

\section{Adrenal tissue}

The adrenal glands of combined weight, $224 \mathrm{mg}$, were taken from a female sheep foetus at 122 days' gestation immediately following its removal from the uterus.

Adult sheep adrenal tissue was obtained at laparotomy under general anaesthesia (pentobarbitone sodium followed by halothane and oxygen) from two ewes, one non-pregnant, the other 104-days pregnant.

\section{Preparation of tissues and conditions of incubation}

The adrenal glands were placed in polythene bags and transported to the laboratory on crushed ice. Experimental work on the tissues was begun within $1 \mathrm{hr}$ of their removal from the animals. The cortical tissue was separated from its capsule and the medulla, and finely chopped using a safety razor blade.

(a) Foetal adrenal tissue. The total amount of foetal cortical tissue $(128 \mathrm{mg})$ was incubated in $1.4 \mathrm{ml}$ Krebs-Ringer bicarbonate-glucose medium for $2 \mathrm{hr}$ at $37^{\circ} \mathrm{C}$ and shaken in an atmosphere of $95 \% \mathrm{O}_{2}: 5 \% \mathrm{CO}_{2}$. The incubation vessel contained $55.4 \mathrm{~m}-\mu$ moles each of $\left[4-{ }^{14} \mathrm{C}\right]$ progesterone $(36 \cdot 1 \mu \mathrm{c} / \mu \mathrm{mole})$ and $\left[7 \alpha-{ }^{3} \mathrm{H}\right]$ pregnenolone $(450 \mu \mathrm{c} / \mu \mathrm{mole})$.

(b) Adult adrenal tissue from a non-pregnant ewe. The total mass of chopped cortical tissue $(2 \cdot 1 \mathrm{~g})$ was incubated in $25 \mathrm{ml}$ Krebs-Ringer bicarbonateglucose medium with $83.3 \mathrm{~m}-\mu$ moles $\left[4-{ }^{14} \mathrm{C}\right]$ pregnenolone $(24 \cdot 0 \mu \mathrm{c} / \mu \mathrm{mole})$, $4.4 \mathrm{~m}-\mu$ moles $\left[7 \alpha^{3}{ }^{3} \mathrm{H}\right]$ progesterone $(2.26 \mathrm{mc} / \mu \mathrm{mole})$ and $4.4 \mathrm{~m}-\mu$ moles unlabelled $17 \alpha$-hydroxypregnenolone. The incubation conditions were identical to those for the foetal adrenal tissue. The unlabelled $17 \alpha$-hydroxypregnenolone, which was equimolar to the $\left[7 \alpha^{3} \mathrm{H}\right]$ progesterone, was added to the incubation to avoid creating an early imbalance in the two major pathways to cortisol from pregnenolone.

(c) Adult adrenal tissue from a pregnant ewe. Cortical tissue ( $1 \mathrm{~g}$ ) was finely chopped and then homogenized in $4.0 \mathrm{ml} 0.25 \mathrm{M}$-sucrose containing nicotinamide $(0 \cdot 12 \mathrm{M})$ in a Philpot \& Stanier (1956) homogenizer. Three 1-ml portions of homogenate were incubated with (i) $10 \mathrm{~m}-\mu$ moles $\left[7 \alpha-{ }^{3} \mathrm{H}\right]$ pregnenolone, (ii) $0 \cdot 25 \mathrm{~m}$ - $\mu$ mole $\left[7 \alpha^{3} \mathrm{H}\right] 17 \alpha$-hydroxypregnenolone and (iii) $10 \mathrm{~m}-\mu$ moles $\left[7 \alpha_{-}{ }^{3} \mathrm{H}\right]-$ dehydroepiandrosterone for $1 \mathrm{hr}$ at $39^{\circ} \mathrm{C}$, in $3 \mathrm{ml}$ incubation medium. This medium consisted of a phosphate buffer, $\mathrm{pH} 7 \cdot 0$, containing $0.025 \mathrm{M}$-magnesium sulphate, 0.02 M-potassium sulphate and 0.01 M-ATP (Pulkkinen, 1966).

The purity of radio-active steroids used as substrates in the incubations was checked by diluting samples with carrier material and chromatographing on 
thin layers and on paper in a number of solvent systems. The specific activities of the free steroid and of two derivatives formed from it, showed the material to be not less than $99 \%$ pure. Radio-active material on chromatograms was detected using a Packard Model 7201 radiochromatogram scanner.

\section{Extraction and fractionation of steroids}

Following the addition of acetone to the incubation, various non-radioactive carrier steroids were added to the mixtures:

Incubation (a). The following carrier steroids (500 $\mu \mathrm{g}$ of each) were added to the incubation: pregnenolone, 17 $\alpha$-hydroxypregnenolone, progesterone, $17 \alpha$-hydroxyprogesterone, $20 \alpha$-hydroxy-pregn-4-en-3-one, (20 $\alpha$-dihydroprogesterone), $20 \beta$-hydroxypregn-4-en-3-one (20 $\beta$-dihydroprogesterone), 11-deoxycorticosterone (DOC), corticosterone, 11-deoxycortisol, cortisol, cortisone, dehydroepiandrosterone (DHA), androstenedione, and the sulphates of pregnenolone, $17 \alpha$-hydroxypregnenolone and DHA. After homogenization in a Silverson mixer, the mixtures were filtered, washed three times with acetone, and the extracts and the washings dried under reduced pressure. Steroids were then extracted and fractionated as previously described (Cameron \& Griffiths, 1968; Griffiths, Gunningham \& Cameron, 1968).

Incubation $(b)$. Carrier steroids, $30 \mu \mathrm{g}$ of each, were added as follows: pregnenolone, 17 $\alpha$-hydroxypregnenolone, 21-hydroxypregnenolone, progesterone, 17 $\alpha$-hydroxyprogesterone, DOG, corticosterone, 11-deoxycortisol, cortisol, cortisone and the sulphates of pregnenolone, $17 \alpha$-hydroxypregnenolone and DHA. The mixture was homogenized, filtered and washed with acetone and the extract and pooled washings were dried. The extract was then divided into two equal portions. A further $300 \mu \mathrm{g}$ of each of the carrier steroids detailed above were added to one half of the extract, and $600 \mu \mathrm{g}$ of each to the other half. The carriers were then isolated as for incubation (a).

Incubation $(c)$. To each of the three incubations, $500 \mu \mathrm{g}$ of the following carrier steroids were added: (i) the sulphates of pregnenolone, $17 \alpha$-hydroxypregnenolone and DHA; (ii) 17 $\alpha$-hydroxypregnenolone sulphate and DHA sulphate; (iii) DHA sulphate.

A conjugated steroid fraction was isolated from each incubation and subjected to chromatography in the solvent system of Pierrepoint (1967). The steroid sulphates were eluted, solvolysed (Burstein \& Lieberman, 1958), and $300 \mu \mathrm{g}$ of carrier androst-5-ene-3 $\beta, 17 \beta$-diol (androstenediol) added to each of the solvolysis extracts. In each incubation, the specific activities of the free steroid and its acetate were measured.

\section{Chromatography, isolation and measurement of steroids}

Thin layer chromatography on Merck silica gel $\mathrm{HF}_{254 / 366}$ was used to isolate the majority of the steroids in the various fractions. Steroids and their derivatives were detected and extracted from silica gel by procedures previously described (Fahmy, Griffiths, Turnbull \& Symington, 1968).

The separation of $20 \alpha$ - and $20 \beta$-dihydroprogesterone was achieved by paper chromatography on Whatman No. 1 paper in the solvent system light petroleum (b.p. 80 to $100^{\circ} \mathrm{C}$ ): methanol: water $(10: 9: 1)$. All other steroids separated 
on thin layers. Steroids were measured after elution and derivatives prepared by procedures already established (Griffiths, Grant \& Whyte, 1963; Griffiths, Grant, Browning, Cunningham \& Barr, 1966). Radio-activity was measured by a Nuclear Chicago liquid scintillation spectrometer (Model 6860). The observations that the specific activities of a steroid and two of its derivatives differed by not more than $10 \%$ was taken as satisfactory evidence for radiochemical purity. The mean of the specific activities was used to calculate the percentage conversion from the original steroid incubated.

\section{Assessment of relative magnitude of alternative metabolic pathways}

A mathematical formula was derived by Cameron, Beynon \& Griffiths (1968) for a semi-quantitative assessment of alternative metabolic pathways from pregnenolone to cortisol in human adrenal tissue incubated in vitro, derived from that described by Kopin (1963). It was shown that if the sum of the percentage conversions to 17 $\alpha$-hydroxyprogesterone+11-deoxycortisol + cortisol+cortisone is $\mathrm{C}_{2}+\Sigma C_{2}$ (Text-fig. 1) and that to DOC+corticosterone is $C_{3}+\Sigma C_{3}$ then

$$
f_{B_{2}\left(C_{2}+\Sigma C_{2}\right)} \bumpeq\left[\frac{{ }^{14} \mathrm{G}}{{ }^{3} \mathrm{H}}\right]_{C_{3}+\Sigma C_{3}} /\left[\frac{{ }^{14} \mathrm{G}}{{ }^{3} \mathrm{H}}\right]_{C_{2}+\Sigma C_{2}}
$$

where $f_{B_{2}\left(C_{2}+\Sigma C_{2}\right)}$ is the fraction of $C_{2}$ and compounds formed from it through the intermediate $B_{2}$, i.e. progesterone, and ${ }^{14} \mathrm{C} /{ }^{3} \mathrm{H}$ ratios are based on the total radio-activity isolated in the compounds referred to as $C_{2}+\Sigma C_{2}$ and $C_{3}+\Sigma C_{3}$ (Text-fig. 1).

This formula was applied to the results obtained in Incubation (b) with adult sheep adrenal tissue.

\section{RESULTS}

The studies on the adult sheep adrenal (Incubation (b)) show that the substrates $\left[4-{ }^{14} \mathrm{C}\right]$ pregnenolone and $\left[7 \alpha-{ }^{3} \mathrm{H}\right]$ progesterone were almost completely metabolized, only $1.3 \%$ and $4.6 \%$, respectively, remaining at the end of the incubation period (Table 1). Approximately $15 \%$ of the incubated pregnenolone was converted to corticosterone, and $12 \%$ and $21 \%$ to 11 -deoxycortisol and cortisol, respectively. These were the major products. In contrast to this, however, only small yields of the 17-hydroxylated compounds were obtained from progesterone, namely $0.04 \% 17 \alpha$-hydroxyprogesterone, $0.19 \% 11$ deoxycortisol, $0.64 \%$ cortisol and $0.16 \%$ cortisone, whereas $32.3 \%$ of the progesterone was converted to corticosterone. Substitution of the percentage conversion figures of $\left[4-{ }^{14} \mathrm{C}\right]$ pregnenolone and $\left[7 \alpha^{-} \mathrm{H}\right]$ progesterone to $C_{2}+\Sigma C_{2}$ and $C_{3}+\Sigma C_{3}$ and hence the derivation of the value of $f_{B_{2}\left(C_{2}+\Sigma C_{2}\right)}$ indicate that approximately only $1.5 \%$ of the 17 -hydroxylated metabolites was formed from pregnenolone by way of progesterone (Text-fig. 1).

During the incubation of human adrenal tissue in vitro, steroids are secreted into the medium. These are derived from endogenous precursors, notably cholesterol, regardless of the exogenous radio-active precursors added. This contribution by the tissue to the total mass of steroid isolated must either be 
negligible, or measured, if reverse isotope dilution analysis is to be accurate. The endogenous steroid output was determined using principles described for the human adrenal cortex by Cameron \& Griffiths (1968) from the results of Incubation (b) (Adult adrenal, Table 1). There was no evidence for significant endogenous steroid synthesis over the 2-hr incubation period.

The experiment with the foetal sheep adrenal tissue showed that the $\left[7 \alpha-{ }^{3} \mathrm{H}\right]-$

TABLE 1

PERGENTAGE RADIO-AGTIVITY FOUND IN ISOLATED STEROIDS AFTER SIMULTANEOUS INGUBATION OF $55.4 \mathrm{M}-\mu$ MOLES EACH OF $\left[4-{ }^{14} \mathrm{G}\right]$ PROGESTERONE $(36 \cdot 1 \mu \mathrm{C} / \mu \mathrm{MOLE})$ AND $\left[7 \alpha-{ }^{3} \mathbf{H}\right]$ PREGNENOLONE $(450 \mu \mathrm{C} / \mu \mathrm{MOLE})$ WITH FOETAL SHEEP ADRENAL TISSUE, AND OF $83.3 \mathrm{M}-\mu$ MOLES $\left[4-{ }^{14} \mathrm{c}\right]$ PREGNENOLONE $(24.0 \mu \mathrm{c} / \mu \mathrm{MOLE})$ AND $4.4 \mathrm{M}-\mu \mathrm{MOLES}$ EAGH OF $\left[7 \alpha-{ }^{3} \mathbf{H}\right]$ PROGESTERONE $(2 \cdot 26 \mathrm{MC} / \mu$ MOLE $)$ AND UNLABELLED $17 \alpha$-HYDROYXPREGNENOLONE WITH ADULT SHEEP ADRENAL TISSUE

\begin{tabular}{|c|c|c|c|c|c|c|}
\hline \multirow{3}{*}{ Steroid isolated } & \multicolumn{6}{|c|}{$\%$ Radio-activity found in isolated steroids } \\
\hline & \multicolumn{2}{|c|}{ Foetal adrenal } & \multicolumn{4}{|c|}{ Adult adrenal } \\
\hline & $\begin{array}{c}\text { From } \\
\text { pregnenolone }\end{array}$ & $\begin{array}{c}\text { From } \\
\text { progesterone }\end{array}$ & $\begin{array}{c}\text { From pre } \\
(*)\end{array}$ & $\begin{array}{c}\text { enolone } \\
(\dagger)\end{array}$ & $\underset{\left({ }^{*}\right)}{\text { From pro }}$ & $\begin{array}{c}\text { esterone } \\
(\dagger)\end{array}$ \\
\hline $\begin{array}{l}\text { Pregnenolone } \\
17 \alpha \text {-Hydroxypregnenolone } \\
21 \text {-Hydroxypregnenolone } \\
\text { Progesterone } \\
\text { 17a-Hydroxyprogesterone } \\
20 \alpha \text {-Dihydroprogesterone } \\
20 \beta \text {-Dihydroprogesterone } \\
\text { DOC } \\
\text { Corticosterone } \\
\text { 11-Deoxycortisol } \\
\text { Cortisol } \\
\text { Cortisone } \\
\text { DHA } \\
\text { Androstenedione } \\
\text { Pregnenolone sulphate } \\
17 \alpha \text {-Hydroxypregnenolone } \\
\text { sulphate } \\
\text { DHA sulphate }\end{array}$ & $\begin{array}{l}3 \cdot 0 \\
0 \cdot 06 \\
41 \cdot 6 \\
3 \cdot 4 \\
0 \cdot 74 \\
0 \\
1 \cdot 82 \\
0 \cdot 32 \\
1 \cdot 9 \\
0 \cdot 27 \\
0 \\
0 \cdot 02 \\
0 \cdot 17 \\
0 \\
0 \\
0\end{array}$ & $\begin{array}{l}0 \\
\frac{0}{66 \cdot 6} \\
1 \cdot 7 \\
1 \cdot 1 \\
0 \\
12 \cdot 4 \\
1 \cdot 9 \\
2 \cdot 4 \\
0 \cdot 20 \\
0 \\
0 \\
0 \\
0 \\
0 \\
0\end{array}$ & $\begin{array}{l}1 \cdot 3 \\
3 \cdot 7 \\
0 \\
0 \cdot 24 \\
0 \cdot 78 \\
\overline{-} \\
4 \cdot 6 \\
14 \cdot 7 \\
12 \cdot 7 \\
21 \cdot 5 \\
0 \cdot 58 \\
\overline{-} \\
0 \\
0 \\
0\end{array}$ & $\begin{array}{l}1 \cdot 3 \\
3 \cdot 6 \\
0 \\
0 \cdot 26 \\
0 \cdot 65 \\
\overline{-} \\
\overline{4} \cdot 0 \\
15 \cdot 2 \\
11 \cdot 9 \\
21 \cdot 5 \\
0 \cdot 45 \\
\overline{-} \\
\overline{0} \\
0 \\
0\end{array}$ & $\begin{array}{l}0 \\
0 \\
0 \\
4 \cdot 6 \\
0 \cdot 04 \\
\overline{-} \\
\overline{4} \cdot 6 \\
32 \cdot 3 \\
0 \cdot 19 \\
0 \cdot 64 \\
0 \cdot 16 \\
\overline{-} \\
0 \\
0 \\
0\end{array}$ & $\begin{array}{c}0 \\
0 \\
0 \\
4 \cdot 5 \\
0 \cdot 04 \\
- \\
\overline{4 \cdot 2} \\
33 \cdot 9 \\
0 \cdot 15 \\
0 \cdot 73 \\
0 \cdot 17 \\
\overline{-} \\
\overline{0} \\
0 \\
0\end{array}$ \\
\hline
\end{tabular}

* Half of extract to which $300 \mu \mathrm{g}$ of carrier steroids were added.

$\dagger$ Half of extract to which $600 \mu \mathrm{g}$ of carrier steroids were added.

- Not investigated.

pregnenolone was extensively metabolized $(\sim 97 \%)$ and evidence was obtained for the formation of the following free steroids: 17 $\alpha$-hydroxypregnenolone, 17 $\alpha$-hydroxyprogesterone, 20 $\alpha$-dihydroxyprogesterone, DOG, corticosterone, 11-deoxycortisol, cortisol, DHA and androstenedione. The yields of cortisol and corticosterone from pregnenolone were small, 0.27 and $0.32 \%$ respectively. Only $34 \%$ of the progesterone was metabolized, and comparison of the conversions of pregnenolone and progesterone to the 17-hydroxylated steroids investigated suggests that, in contrast to the adult, 11-deoxycortisol and cortisol in foetal tissue may be formed from pregnenolone by way of progesterone and $17 \alpha$-hydroxyprogesterone.

An interesting finding from these incubations in both adult and foetal sheep adrenals was their apparent inability to form the sulphates of pregnenolone, 
17 $\alpha$-hydroxypregnenolone and DHA, even when optimal conditions for such enzyme systems were provided. Although pregnenolone sulphate from Incubation (c) (i) was lost at the solvolysis stage, there was no evidence for its formation from Incubations $(a)$ and (b).

Table 1 shows that although, in the foetal adrenal, most of the radio-activity from the substrate progesterone was accounted for in the steroids isolated $(86 \%)$, this was not the case for the adult adrenal $(42 \%)$. With regard to the

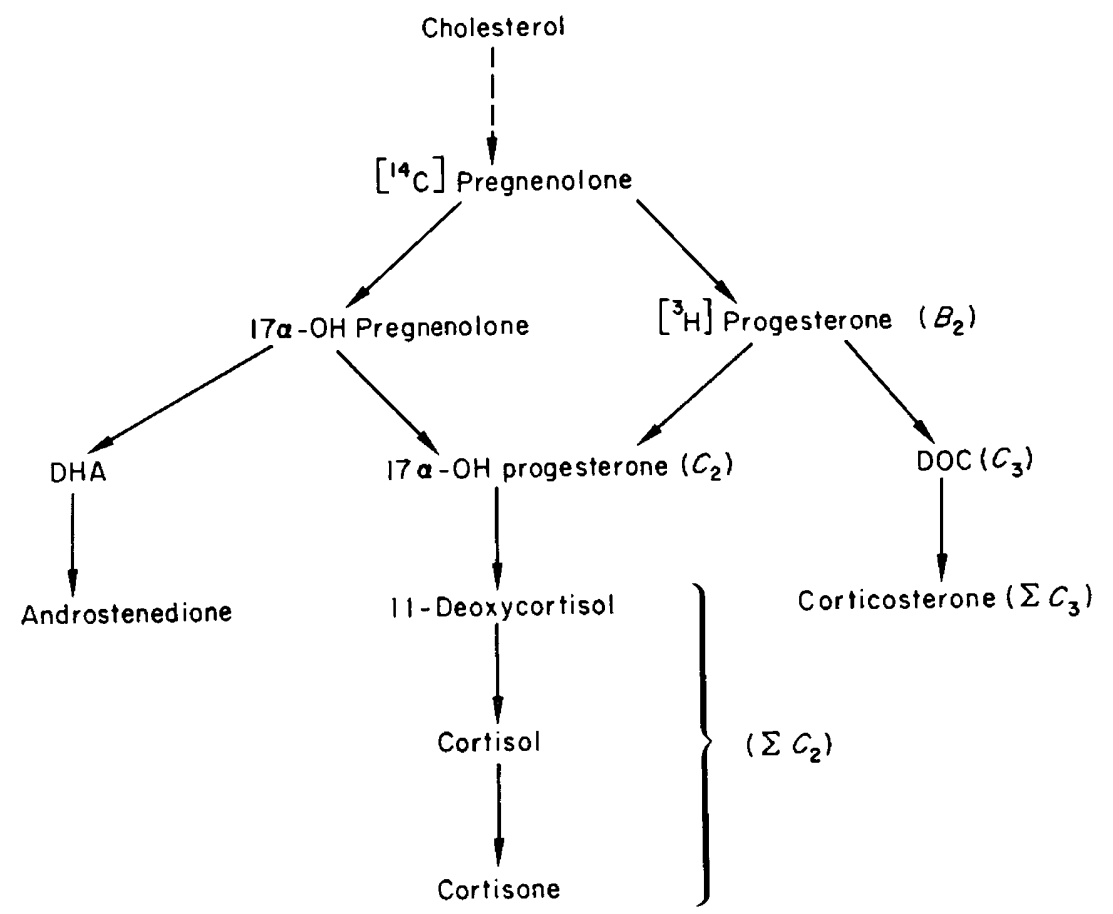

TEXT-FIG. 1. Pathways of corticosteroid biosynthesis showing relationship of the steroids to the components of the formula (see text) derived from that of Kopin (1963).

substrate pregnenolone, only $53 \%$ and $60 \%$ of the radio-activity was recovered in the steroids isolated from the foetal and adult glands, respectively. An attempt was made in the foetal adrenal incubation to identify the unknown metabolites of pregnenolone using radiochromatographic scanning following chromatography on thin layers of silica gel and on paper. One large radio-active peak of greater polarity than any of the steroids investigated eventually resolved into a series of smaller peaks when re-chromatographed in a more polar solvent system.

\section{DISGUSSION}

The present investigations show extensive metabolism of $\left[4-{ }^{14} \mathrm{C}\right]$ pregnenolone and $\left[7 \alpha-{ }^{3} \mathrm{H}\right]$ progesterone by adult sheep adrenal tissue in vitro. Furthermore, it was shown that $54 \%$ and $38 \%$, respectively, of these substrates were converted to corticosteroids, but of apparently greater importance was the demonstration 
that cortisol $(21 \%)$ was the major metabolite formed from pregnenolone, whereas progesterone was transformed mainly to corticosterone $(32 \%)$. Since corticosterone was formed from both precursors in relatively high yield, in contrast to cortisol which was produced in any quantity only from pregnenolone, our in vitro findings are at variance with in vivo studies which have shown that cortisol is secreted in very much greater amounts than corticosterone by the adult sheep adrenal (Blair-West et al., 1963; Chester Jones et al., 1964; Alexander et al., 1968; Bassett \& Hinks, 1969). These findings suggest that, in vivo, the sheep adrenal gland may use pregnenolone in preference to progesterone for the synthesis of these corticosteroids. In the adult adrenal incubation, the prime interest was to assess the formation of corticosteroids and little attempt was made to identify other metabolites. Identification of these unknown metabolites of pregnenolone is a subject of our continuing investigations.

Text-figure 1 indicates the two principal pathways which have been determined for the biosynthesis of cortisol in the human adrenal cortex, one involving 17-hydroxylation of pregnenolone followed by $3 \beta$-hydroxysteroid dehydrogenation and $\Delta^{5}-\Delta^{4}$ isomerism to $17 \alpha$-hydroxyprogesterone, the second requiring the conversion of pregnenolone to progesterone with subsequent $17 \alpha$-hydroxylation to give $17 \alpha$-hydroxyprogesterone. The results in the adult sheep adrenal show that most of the incubated progesterone was converted to DOG and corticosterone $(36.9 \%)$, whereas only $1.03 \%$ was transformed to $17 \alpha$-hydroxyprogesterone, 11-deoxycortisol, cortisol and cortisone. This suggests that cortisol is formed by way of $17 \alpha$-hydroxypregnenolone and substitution of the conversion figures into the equation described earlier indicates that only a small amount of the cortisol is formed from pregnenolone by way of progesterone. Criteria for the validity of the formula are not strictly met in an in vitro system, but nevertheless, even with allowance for reasonable errors, derived figures suggest that the biosynthetic pathway for 17-hydroxysteroid formation from progesterone is not active. Any progesterone formed in the tissue is rapidly converted to the 17-deoxycorticosteroids. These results are very similar to those determined for human adrenal tissue (Cameron \& Griffiths, 1968).

Although Vinson (1967) showed that the pathway pregnenolone $\longrightarrow$ 21-hydroxypregnenolone $\longrightarrow$ DOC was concerned in the synthesis of corticosterone, there was no radio-activity isolated in 21-hydroxypregnenolone in the adult sheep incubation studies reported here. However, the disparity between the ${ }^{3} \mathrm{H}:{ }^{14} \mathrm{C}$ ratios of progesterone and the metabolites DOG and corticosterone, would support the concept of a pathway from pregnenolone to corticosterone which does not involve progesterone. Since no radio-activity accumulated in the biosynthetic intermediate, 21-hydroxypregnenolone, the error in the mathematical assessment of the activity of the metabolic pathways will be relatively small.

In the adult sheep adrenal incubation in which the steroid extract was halved and different amounts of carrier steroids added, the results indicated that there had been no significant endogenous formation of steroids during the time of incubation. This may not be surprising since the sheep has a cholesterolpoor adrenal cortex (Symington, 1960; Griffiths, 1960; Lloyd, cited by Gans \& Shaefer, 1968). 
These experiments have also demonstrated the ability of the foetal sheep adrenal, at 122 days' gestation, to metabolize pregnenolone and progesterone in vitro to a variety of steroids. The large conversion of $\left[7 \alpha-{ }^{3} \mathrm{H}\right]$ pregnenolone to progesterone (Table 1) confirms the findings of Vinson (1967) that this $\Delta^{5}-3 \beta$-hydroxysteroid dehydrogenase-isomerase is present in the adrenal of the sheep foetus.

The results obtained with the foetal adrenal suggest that, not only was the progesterone transformed as efficiently to the $17 \alpha$-hydroxycorticosteroids as was pregnenolone, but that it was itself formed in good yield from this $\Delta^{5}$ substrate. The pathway pregnenolone $\longrightarrow 17 \alpha$-hydroxypregnenolone $\longrightarrow$ 17 $\alpha$-hydroxyprogesterone $\longrightarrow$ 11-deoxycortisol $\longrightarrow$ cortisol cannot then be considered the favoured route for cortisol synthesis from pregnenolone in the sheep foetal adrenal at this stage of pregnancy. Of further interest was the observation that $0.17 \%$ of the pregnenolone was converted to androstenedione compared with $0.27 \%$ to cortisol, whereas no androstenedione was formed from progesterone, suggesting that DHA and not $17 \alpha$-hydroxyprogesterone may be the immediate precursor of androstenedione. The yields of progesterone from pregnenolone and of 11-deoxycortisol and DOC from both pregnenolone and progesterone suggest that the $17 \alpha$-hydroxylating and $11 \beta$-hydroxylating enzyme systems are relatively inactive at this stage of gestation. The findings in the adult sheep adrenal, on the other hand, suggest a deficiency of only a progesterone $17 \alpha$-hydroxylase. This interpretation is in contrast to that of Vinson \& Whitehouse (1967), who found little difference in the steroid biosynthetic pathways of foetal and adult sheep adrenals.

The studies with minced foetal and adult sheep adrenal tissue failed to demonstrate steroid sulphokinase activity. It appears, therefore, that the sheep adrenal, in marked contrast to the human adrenal, does not synthesize DHA sulphate which is so closely involved in oestrogen synthesis in the human foeto-placental unit (Bolté, Mancuso, Eriksson, Wiqvist \& Diczfalusy, 1964).

\section{ACKNOWLEDGMENTS}

The authors wish to record their appreciation of the generous financial support of the Wellcome Trust and the facilities provided by the Tenovus Organization in Cardiff. They also express their gratitude to the Research Committee and Staff of the animal house and research laboratory at Sully Hospital, Glamorgan, for providing such excellent operating facilities.

\section{REFERENCES}

Alexander, D. P., Britton, H. G., James, V. H. T., Nixon, D. A., Parker, R. A., Wintour, E. M. \& WRIGHT, R. D. (1968) Steroid secretion by the adrenal gland of foetal and neonatal sheep. 7. Endocr. 40, 1.

BASSETT, J. M. \& Hinks, N. T. (1969) Micro-determination of corticosteroids in ovine peripheral plasma : effects of venipuncture, corticotrophin, insulin and glucose. 7. Endocr. 44, 387.

Bassett, J. M. \& Thorburn, G. D. (1969) Foetal plasma corticosteroids and the initiation of parturition in sheep. F. Endocr. 44, 285.

Blair-West, J. R., Coghlan, J. P., Denton, D. A., Goding, J. R., Wintour, M. \& Wright, R. D. (1963) The control of aldosterone secretion. Recent Prog. Horm. Res. 19, 311. 
Bolté, E., Mancuso, S., Eriksson, G., Wiqvist, N. \& Diczfalusy, E. (1964) Studies on the aromatisation of neutral steroids in pregnant women. 2. Aromatisation of dehydroepiandrosterone and its sulphate administered simultaneously into a uterine artery. Acta endocr., Copenh. 45, 560.

Burstern, S. \& Lieberman, S. (1958) Hydrolysis of ketosteroid hydrogen sulfates by solvolysis procedures. F. biol. Chem. 233, 331 .

Gameron, E. H. D., Beynon, M. A. \& Griffrths, K. (1968) The role of progesterone in the biosynthesis of cortisol in human adrenal tissue. $\mathcal{F}$. Endocr. 41, 319.

Cameron, E. H. D. \& Gripfrths, K. (1968) Corticosteroid synthesis in a clear cell adenoma: a timebased study. J. Endocr. 41, 327.

Chester Jones, I., Jarretr, I. G., Vinson, G. P. \& Potter, K. (1964) Adrenocorticosteroid production of foetal sheep near term. 7 . Endocr. 29, 211.

Fahmy, D., Griffiths, K., Turnbule, A. C. \& Symington, T. (1968) A comparison of the metabolism in vitro of $\left[7 \alpha_{-}{ }^{3} \mathrm{H}\right]$ dehydroepiandrosterone sulphate and $\left[4-{ }^{14} \mathrm{C}\right]$ pregnenolone by tissue from a hilus cell tumour of the ovary. 7 . Endocr. 41,61.

Gans, J. H. \& ShaEFER, J. (1968) Effects of steroids and ACTH on pyruvate and acetate metabolism by the sheep adrenal cortex in vitro. Endocrinology, 82, 995.

Grifriths, K. (1960) The metabolism of steroids in the adrenal cortex. Ph.D. thesis, University of Edinburgh.

Griffiths, K., Cunningham, D. \& Cameron, E. H. D. (1968) A comparison of the conversion in vitro of pregnenolone sulphate and pregnenolone to steroid hormones by tissue from a clear cell adenoma of the adrenal gland. $\mathcal{F}$. Endocr. 40, 49.

Griffiths, K., Grant, J. K., Browning, M. C. K., Cunningham, D. \& Barr, G. (1966) Steroid biosynthesis in vitro by tissue from a granulosa cell multilocular cystadenoma. F. Endocr. 35, 299.

Griffiths, K., Grant, J. K. \& Whyte, W. G. (1963) Steroid biosynthesis in vitro by cryptorchid testes from a case of testicular feminisation. F. clin. Endocr. Metab. 23, 1044.

KopIn, I. J. (1963) Estimation of magnitudes of alternative metabolic pathways. Meth. biochem. Analysis, $11,247$.

Liggins, G. C. (1968) Premature parturition after infusion of corticotrophin or cortisol into foetal lambs. 7. Endocr. 42, 323.

Philpot, J. St. L. \& Stanier, J. E. (1956) The choice of the suspension medium for rat liver cell nuclei. Biochem. 7. 63, 214.

Pierrepoint, G. G. (1967) The separation of neutral steroid sulfates by thin-layer chromatography. Analyt. Biochem. 18, 181.

Pulkkinen, M. O. (1966) Sulphate conjugation during development in human, rat and guinea pig. Acta physiol. scand. 66, 115.

Symington, T. (1960) The morphology of the adrenal cortex In: The Biosynthesis and Secretion of Adrenocortical Steroids, p. 40. Eds. F. Clark and J. K. Grant. Cambridge University Press.

Vinson, G. P. (1967) Role of 21-hydroxypregnenolone in the synthesis of corticosterone from pregnenolone by sheep adrenal tissue in vitro. Gen. $\mathcal{E}$ compar. Endocr. 9, 154.

Vinson, G. P. \& Whrrenouse, B. J. (1967) The biosynthesis of corticosteroids by sheep and human adrenal tissue. Acta endocr., Copenh. Suppl. 119, 68. 